\title{
The Effectiveness of Cultivated Land Protection and Strategies in China
}

\author{
Meiqiu Chen, Taoju Liu, Bingjuan Zhou, Xinglu Xu \\ The MPA Education Center ,Jiangxi Agriculture University/ Jiangxi Provincial Research Center for Agricultural Ecology of \\ Poyang Lake Watershed, Nanchang 330045,China \\ cmq12@263.net
}

\begin{abstract}
As a huge country with 1.3 billion population, protecting cultivated land is a basic policy in China. In this paper, the implementation effectiveness of cultivated land protection and causes since the reform and opening were analyzed, and the results shows that: China has proposed the basic farmland protection system, "rice bag" governor accountability, "total dynamic balance of cultivated land" and other important cultivated land protection policy, these policies have played a relevant role in curbing the cultivated land decreasing trend, but the overall quality of the cultivated land decreased, and the main causes are the lack of protection of cultivated land real executive body, the externality of cultivated land protection has not been widely recognized. Therefore, some countermeasures were put forward: creating an atmosphere of cultivated land protection participated by the whole society; motivating the positivity of peasants in cultivated land protection; strengthen the social support to the cultivated land protection.
\end{abstract}

Keywords: cultivated land protection policy; review; effectiveness analysis; countermeasures; China

As a huge country with 1.3 billion population, the food security must rely on self-supply in China. However, since the opening-up system in 1978, with the progress of urbanization and industrialization, the conflicts between needs for construction land and cultivated land protection become increasingly severe. The central government has constantly enhanced their strength on cultivated land protection and formulated the basic national policies to protect cultivated land. Nowadays, for China is in the accelerating phase of urbanization and industrialization, the cultivated land is still threatened to be occupied by various construction projects. There is still a long way to go. It is necessary to analyze the cultivated land protection policies of our country and conclude their successes and failures so as to further improve our cultivated land protection policies and provide reference for more effective protection of cultivated land.

\section{A REVIEW ON The CULTIVATED LAND PROTECTION IN CHINA}

Since opening-up in 1978, some landmark policies on cultivated land protection have been formulated, such as basic farmland protection system, "rice bag" provincial governor responsibility system and dynamic equilibrium of total cultivated land.

\section{A. Basic Farmland Protection System}

In 1988, the first basic farmland protection area was born in Zhoulaozhui town, Jianli County, Hubei province. In 1989, the Conference of National Basic Farmland Protection was jointly held by the former National Land Administration Bureau and Agricultural Department in Jinzhou, which stood for the establishment of basic farmland protection system[1]. Later, the government stipulated a series of distinct policies and rules pertaining to the basic farmland protection, such as Notice of Administration and Protection of Cultivated Land by the CPC Central Committee and the State Council in 1997, Land Management Law in 1998 and Regulation on the Protection of Basic Farmland by the State Council. Since then, the protection of basic farmland became a fundamental policy in the protection of cultivated land of China.

System of basic farmland protection is an unprecedented innovation in the history of China, which does not only complete the land administration system, successfully exploring the administration of construction land and cultivated land by zoning plan, but also provides useful experience for the establishment of administration system of land use, performing a significant role in the cultivated land protection in our country [2]. For instance, the total area of basic farmland is increased up to over $80 \%$ of the cultivated land, with more than 1.58 billion acres, which means that the consciousness of protecting cultivated land has been substantially strengthened by the zoning plan of basic farmland, establishment of protection systems as well as popularization of the basic national policies. The occupancy of basic farmland for other uses should be strictly examined and approved by the government so as to control the reduction of cultivated land in a maximal degree. Besides special protection to the basic farmland, more capital should be invested in the construction of basic farmland and improvement of cultivated land quality. Especially, with the promotion of nation-level demonstration area of basic farmland protection, the construction of agricultural modernization has been significantly accelerated.

\section{B. "Rice Bag" Provincial Governor Responsibility System}

Since the 1990s, the total output of grain has fluctuated and even stopped increasing. For instance, there were 446.24 million ton in 1990 , which reduced to 435.92 million ton in 1991, bounced to 442.66 million ton in 1992, and then rose up to 456.44 million ton in 1993, and later reduced 
again to 444.60 million ton in 1994(1.64 million ton less than that of 1990). From the perspective of grain demand and supply relationship in regions, the former "grain supply transported from the south to the north" changed into "grain supply transported from the north to the south". For example, the Yangtze River Delta and the Pearl River Delta have become main grain importers from the former exporters. (In 1994, nine out of twelve coastal areas suffered grain output reduction, with a total reduction of 6.95 million ton, which was over $57.9 \%$ of the total grain reduction.) Therefore, the government emphasized in the Government Work Report in March of 1995 that we must insist on the implementation of "rice bag" provincial governor responsibility system [3].

The main contents of "rice bag" provincial governor responsibility system are: with the provinces as regional areas, with the provincial governors responsible for the whole system, each region is required to realize the balance between grain demand and supply and to maintain the comparative stability of grain market, specifically including the stable production by increasing the total grain output; grain resource stability by ensuring its purchase amount; grain storage stability by gradually establishing a grain storage system; and finally price stability by arranging the grain adjustment and ensuring its supply among regions.

The promulgation of "rice bag" provincial governor responsibility system has improved the grain production in a short time and exerted a positive influence on the balance between grain demand and supply, strengthening the sense of responsibility of provincial governors and leaders. While making efforts to increase the grain output, governments of each level are concentrating on some profound problems which restrict the grain production, such as increase of the peasants' income by various channels. More financial investment has been put on the agriculture and agricultural technologies, construction of water conservancy, improvement of grain producing conditions as well as promotion of their ability to combat natural adversities. In order to motivate the positivity of peasants, some local governments gave extra subsidies to peasants beyond ordered grain price and awarded those of good harvest. As a result, the cultivated area of grain has recovered and the grain output has grown rapidly. For instance, the total grain output of 1995 and 1996 were up to 466.618 million ton and 504.535 million ton respectively. However, "rice bag" provincial governor responsibility system depends on administrative methods not economic market methods to maintain the grain production, which conflicts with the constant development of market economy. On one hand, few local governments regard self-balance as balance of each level, with each level of government having their own responsibilities. It just scratches the surface of the problem. On the other hand, it conflicts with the macro-control of the central government. For instance, in 1995, when there was a short supply of grain in the market, the country stabilized the grain price with special grain storage for many times. However, during this period, many local governments refused to supply their grain storage; instead, they even stored up grain, which led to the grain storage of various levels: provincial, municipal and county level. Therefore, "rice bag" provincial governor responsibility system has gradually been given up by the governments [4]. By now, it is mentioned no longer.

\section{Dynamic Equilibrium of Total Cultivated Area}

Since the 1990s, the cultivated land per capita in our country has still been in decline, with an annual speed of 0.001 hectare per capita. The cultivated land per capita was reduced from 0.1164 hectare in 1990 to 0.1079 hectare in 1995 [5]. In 1995, Who Will Feed China? by Lester Brown shocked China and the whole world [6]. According to Brown, with population growth and improvement of food structure in China, the food demand in China will increase sharply. But industrialization and traffic construction have led to the sharp decline of cultivated land in China. The limited promotion of technological advances and the negative influence of environment pollution on the agricultural productivity will lead to the short supply of grain. If China-a populous country has the food problem, it will threaten this kind of situation in the whole world. In order to put off the doubts of international community, the Chinese government has solemnly claimed for many times that we can rely on ourselves. In 1996, the Chinese government brought up the dynamic equilibrium strategies of total cultivated land.

Dynamic equilibrium of total cultivated area aims to protect the land productivity so as to meet people's needs in the planned areas. Actually, it is the dynamic equilibrium of cultivated land productivity [7]. Since this strategy was brought up, there existed some negative phenomena such as emphasis on quantity equilibrium instead of quality equilibrium and occupancy of fertile land made up by barren land [8-9]. In this case, correspondent policies have been constantly improved. For instance, in 1998, it was clearly stipulated that "occupy one compensate one "policy was adopted in the occupancy of cultivated land by construction land[10]. The former "occupy first compensate later" or "occupy while compensate" have been changed into "compensate first occupy later". The cultivated land has been graded in various degrees. And great efforts have been put into the practice of occupy-subsidy conversion. Besides, restrictive index has been brought up to ensure cultivated land of 1.8 billion hectares. According to dynamic equilibrium strategy of total cultivated area, the "occupy one compensate one" policy adopted in the occupancy of cultivated land by construction land significantly increased the occupancy cost of cultivated land by construction projects, which has exerted a great influence on the restriction of cultivated land occupancy by construction usage.

\section{ANALYSIS OF THE EFFECTS OF CULTIVATED LAND PROTECTION IN CHINA}

\section{A. The Trend of Cultivated Land Reduction Being Suppressed}

Since the opening-up policy, we have strengthened our protection of cultivated land and made some achievements. Especially in recent years, the "occupy one compensate one" 
policy was adopted in the occupancy of cultivated land by construction land. As a result, the trend of cultivated land reduction has been suppressed. However, due to the colossal population and inertial growth, the reduction of cultivated land per capita has not been reversed, with 0.1164 hectare per capita in 1990 , reduced to 0.1012 hectare in 2000 and 0.0917 hectare in 2008 .

Let us have a further analysis of the reduced cultivated land between 1997 and 2008. 12.2989 million hectares have been reduced in twelve years with $58.83 \%$ ecological restoration and $20.09 \%$ for construction usage. The agricultural structure adjustment and disasters were $15.11 \%$ and $5.98 \%$ respectively. Replenishment land reclamation by land exploration were 3.5517 million hectares, with a net reduction of 8.7472 million hectares. Moreover, the areas of replenishment land reclamation by land exploration were more than that for construction use. In this case, the occupancy-compensate of cultivated land has recovered to a balance.

When we analyse the annual reduced cultivated land, we will find that the ecological restoration vary most among years. It reached its climax in 2003, which is closely related to its national policies. However, the cultivated land for construction use has been maintained in a certain level, which means that there is no change in the annual occupancy of cultivated land for construction use and the effects of occupied cultivated land for construction use are not obvious.

\section{B. The Cultivated Land Quality is Declining in General}

Although governments of each level are required to implement a balanced policy between land occupancy and compensation, the occupied fertile cultivated land is made up by sterile land in most areas. For instance, a lot of fertile land around towns and traffic lines occupied is yet made up by barren land in some remote mountain areas with severe natural conditions and underdeveloped irrigation facilities [11-12]. In 2005, among the occupied cultivated land for construction use, $67 \%$ were equipped with irrigation facilities, while among the land made up by construction, only $35 \%$ were equipped with irrigation facilities [13]. According to the statistics of Agricultural Department, in the recent decades, the newly-reclaimed land is 2 or 3 times worse than the occupied cultivated land for construction use. Its productivity is less than $30 \%$ of occupied cultivated land for construction use. The productivity of land made up by construction is 200 kilograms per hectare than that of occupied cultivated land [14].

Among the present cultivated land, paddy field and dry land are $23.11 \%$ and $76.89 \%$ respectively of the total area of cultivated land, with only $22.6 \%$ irrigable land among the dry land. However, the area of slopping farmland which is barren and thin, of low productivity occupies $35.1 \%$ of the total cultivated land [15]. Besides, according to the results of Investigation and Evaluation of the Cultivated Land Quality in China in 2009, the cultivated land of good, high, moderate and low grades were respectively $2.67 \%, 29.98 \%, 50.64 \%$ and $16.71 \%$, among which cultivated land of moderate or low grades occupies two thirds

\section{Problems AND REASONS In THE PROTECTION OF CULTIVATED LAND IN CHINA}

\section{A. Lack of Real Executive Subjects in the Cultivated Land Protection}

It cannot be denied that the central government has claimed for many times that China will adopt the strictest cultivated land protection system in the world, which demonstrates our resolute confidence in the cultivated land protection. However, due to the lack of real executive subjects, various regulations and rules pertaining to cultivated land protection have not been fully executed in the reality.

1) Low productivity and unstable expected benefits cool down the peasants positivity in cultivated land protection. Theoretically, the peasants feed on their cultivated land and cultivated land is the most important thing to them, so they are supposed to protect the cultivated land in their best efforts. However, in reality, the peasants' positivity in cultivated land protection is not as high as we imagine [16]. The long-term dualistic structure of social economic development mode in China has led to the huge gap between the cities and the countrysides. Most peasants regard the enjoyment of urban civilization in the cities as their ultimate goals. Due to the long-term scissors difference between industrial and agricultural products and constantly increasing cost of agricultural production, the economic profits of agricultural production are very low, with the frequent phenomenon of "increasing productivity vs. reducing income". Therefore, many peasants hold that insistence on farmland protection is to maintain poverty. There is a contradiction between "protect the farmland" and "maintain poverty". The State Council has emphasized to protect the peasants' operation right of contracted land and promulgated the Law of the People's Republic of China on Land Contract in Rural Areas, stipulating that during the contract period, the contractor is not allowed to take back his contracted land nor adjust it. It safeguards the peasants' expectation for lawful operation of land. But many peasants still have doubt for the stability of the expected profits of the cultivated land. Meanwhile, due to the abuse of land acquisition system by local governments, peasants are deprived of equal status during the negotiation. So they are afraid that their contracted land will be expropriated by the government, which struck their positivity to protect cultivated land.

2) Fuzziness of subjects in collective land ownership weakens the responsibility of village collective organization to cultivated land protection. According to the Land Management Law, land collectively owned by peasants belongs to all peasants as a collective, operated and administered by the village collective economic organization or the villagers' committee. However, nowadays the collective economic organization in most 
regions of our countryside only exist in name. Besides, villager collective organization is only an abstract concept, because there is a lack of organizational forms or procedures pertaining to the implementation of collective land ownership. Though the village collective economic organization and villagers' committee are regulated as the operator and administrator of collective land, these organizations are just the operator or administrator not owner of the collectively-owned-land. In reality, the representatives of collective land owners are usually the village head or a few people in the villagers' committee. In this case, land collectively owned by peasants becomes land owned by a clique of village cadres, which leads to the subject dislocation of collective land ownership. In order to pursue personal benefits, the clique may make a fortune by cultivated land conversion. In this case, a lot of cultivated land has been employed for other uses, which is a an obstacle in the protection of cultivated land.

3) The failure of local governments in cultivated land protection aggravates the situation of cultivated land being occupied for construction use. As the direct administrator of cultivated land protection, the local governments do not shoulder their responsibility in cultivated land protection. On the contrary, they even take the initiative to occupy the cultivated land illegally. Many local governments expand their land exploration and establish various development gardens. In some cities or towns, there are a large area of explored land which is waiting to be put into other uses. In 2003, there are 6015 development gardens of 35.4 thousand square kilometers, which are mainly the results of the local governments' behaviours. Why is there a huge different between the attitudes of the central government and the local governments toward cultivated land protection? So what drives the local governments to occupy so much cultivated land? There are two main reasons. One is to maintain the regular operation of local governments. At present, the central government and the local governments in our country are separated from each other on the financial systems. For the local governments, land transferring fees are an important revenue beyond their regular budget capital, so "make a fortune on the land" becomes the highest standard in the land administration of many local governments. The other reason is that the transferring of cultivated land to construction uses can help build more achievements in one's official career, for the evaluation standards of one's governmental achievements depend on its local economic profits, such as GDP growth, scale of town development, number of foreign investment, number of industrial projects, etc. Since the cost of cultivated land occupancy is low and it can demonstrate the political achievements of a governor, governments in some places call for "a small change in a year; a huge change in three years". In order to attract the investment, some governments agree to give out their land for free. In this case, more and more cultivated land is occupied for commercial or construction use.

\section{B. The Externalities of Cultivated Land Protection Have Not Been Widely Recognized by the Society.}

Cultivated land does not only bring economic profits to peasants, but also provides a large amount of nonproductive functions for the society, such as social stability based on food security, peasant employment and insurance, traditional culture of farmland cultivation, open space, unique scenery of the countryside, habitat for wild life, purification of air and underground water, etc [17]. Cultivated land is of strong characteristics of economic externalities and of unique space characteristics. One is the externalities of intra-generation and inter-generation, that is, the reasonable distribution of resources should be considered both from the benefits of our generation and our posterity. On the other hand, due to the unbalanced distribution of cultivated land space, difference between the benefits of cultivated land and non-agricultural land, unbalanced development of regional economies, etc, the externalities of cultivated land protection often break its spatial borders and demonstrate extension in the spatial space [18].With a huge land area and obvious distinction between the southeast and the northwest, China is in an unbalanced economic development, especially in the agricultural area of underdeveloped where the cultivated land is in better protection and with more harvest of grain. Of course, they cost more in the cultivated land protection. But the non-productive effects produced by cultivated land are equally shared by developed areas. The cost in cultivated land protection paid by the peasants is in proportion to the area of cultivated land owned by them. So the more area of cultivated land a peasant owns, the more he has to cost in its protection and the more responsibilities he has to shoulder, the more the loss of ecological and social benefits brought by cultivated land protection. Therefore, in order to maintain the fairness of cultivated land protection, the responsibilities of it should be elevated to the whole society who will share the cost of cultivated land protection.

The economic profits produced by the operation of cultivated land can be enjoyed by the operator alone, but the social and ecological benefits brought by cultivated land protection should be shared by all members of the whole society. One's share of the social and ecological benefits brought by cultivated land protection does not exclude other people's share of them, so the phenomenon of free ride is inevitable. As the users of cultivated land, peasants have no capability to control this phenomenon, which will weaken the peasants' positivity in cultivated land protection to some extent and lower the public efficiencies of social and ecological benefits and finally have a negative influence on the cultivated land protection. For cultivated land is public property, the whole society should shoulder the responsibility of cultivated land protection so as to improve the public efficiency and maintain the virtuous circle. The whole society should give support to the peasants in cultivated land protection. In this case, the positivity of the peasant will be facilitated. Moreover, the cost in cultivated 
land protection paid by the peasants should be shared by the society, which also reflects the fairness of social benefits.

\section{Discussion On The StRategies Of Cultivated LAND PROTECTION}

\section{A. Creating an Atmosphere of Cultivated Land Protection Participated by the Whole Society}

The strategical goal of cultivated land protection cannot be achieved until the positivity of the whole society is motivated and all people participate in the cultivated land protection, which proves successful in other countries' experience in cultivated land protection. It is required to attract the participation of the whole society in cultivated land protection by creating an atmosphere of cultivated land protection. First and foremost, we should strengthen our theoretical research on the social responsibilities of cultivated land protection, especially fundamental research on the subjects and methods of responsibility assuming, which provides theoretical support to the participation of the whole society in cultivated land protection. Secondly, we should increase our promotion on the non-productive functions of cultivated land so as to increase the awareness of cultivated land protection in the whole society.

We should emphasize the significance of cultivated land protection non only in the insurance of food security and maintenance of social stability, but also the ecological functions provided for the society in the aspects of traditional culture of farmland cultivation, open space, unique scenery of the countryside, habitat for wild life, purification of air and underground water, etc. In this case, the peasants will realize that the cultivated land not only brings them economic profits but also many ecological benefits for the whole society. The whole society is the beneficiary of cultivated land protection. Thirdly, we should also improve the social responsibility supervision mechanism of cultivated land protection. Fourthly, cultivated land protection should be contained in the benefit farming policies of the country. China has entered the phase of"agriculture promoted by industry and countryside promoted by cities". In recent years, the country has promulgated a series of benefit farming policies, such as direct subsidy to grain producers, subsidy for superior grain cultivators, comprehensive subsidy for agricultural production materials, subsidy for purchase of agriculture facilities, etc. There is great commonness between the benefit farming policies and cultivated land protection. The cultivated land protection should be taken into consideration when the improvement of benefit farming policies.

\section{B. Motivating the Positivity of Peasants in Cultivated Land Protection}

Peasants are the key subjects in cultivated land protection, playing a core role both in the quality and quantity of cultivated land protection. This is because the quality of cultivated land is closely related to the varieties of plants, choice of cultivating system, use of chemical fertilizer and farmyard manure, use of pesticide as well as irrigation methods, which cannot be separated from the participation of peasants. Meanwhile, with the reform of acquisition system, peasants participate more and more in the transferring of cultivated land for other uses, during which peasants show more subjectivity [19].

At present, there are three main reasons influencing the positivity of peasants in cultivated land protection. Firstly, the economic profits of cultivated land operation is low. Since the price of agricultural products and the income of peasants is low, peasants are not willing to engage in farming. Secondly, the basic construction of farmland cannot be safeguarded by the few number of labours in the countryside. For working in the city is the main channel to increase the income of peasants, people stay in the countryside are mainly women, children and old people who are not able to shoulder the duties of applying fertilizer, building water conservancy and improving soil conditions. Thirdly, because of the absolute fairness required in family contract system, most farmland are separated into small pieces of unbalanced conditions, which is an obstacle to the large-scaled farmland operation. Therefore, proper measures should be employed to motivate the positivity of peasants. On one hand, the government should give further support to agriculture, peasants and countryside so as to improve the economic profits of agricultural production. The concept of "protect farmland is to maintain poverty" should be eliminated. On the other hand, the urban environment should be improved so that people from the countryside can really make a living in the cities. In this case, the original source of cultivated land transferring can be strengthened. Thirdly, the social insurance system should be gradually established in the countryside. The farmland in the countryside should transform to capital function from insurance function in proper times. When the social insurance of peasants rely on their cultivated land, transferring of land to the good cultivators should be further promoted, which is conductive to the realization of agricultural modernization [20].

\section{Strengthen the Social Support to the Cultivated Land Protection}

1) Speeding up the reform of land acquisition system and increase the cost of land occupancy for construction use. Strict distinction should be made between public benefit and profit winning of land occupancy for construction use. While gradually narrowing of acquisition range, focus should be paid on the compensation mechanism of acquisition. Land expropriation should conducted according to he Land Management Law, including land compensation fee, resettlement fee, compensation fee for structures on the ground and young crops, etc. The employment, accommodation and social insurance of peasants should also be properly solved, which not only safeguard the basic rights of peasants whose land has been in acquisition but also avoid the employment of cultivated land for construction use. When the cost of acquisition is increased, the cost of cultivated land occupancy will be higher than that of non-cultivated land occupancy and that of 
construction within the city. Only in this case, the fertile land can be protected from acquisition, which is also conductive to the reservation of land resources.

2) Promoting the reform of financial system and suppress the trend of non-agricultural use of cultivated land. We should correct our concepts pertaining to urban development and make clear that "land is the second finance". When there is lack of capital for urban development, it cannot be blamed to transfer the land for the collection of capital for urban development. But it is theoretically false to regard the transferring of land as the long-term financial income of the government. Besides, the urban development will be misled in the reality. The overly expansion of urban development will seriously threaten the cultivated land protection. Therefore, we have to stop the occupancy of cultivated land by the local governments. Moreover, we have to reform the present financial system, ensuring the financial expenditure of the local governments, especially township governments. The financial power should be united with the authority. Furthermore, the functions of governments should be transformed into small organs who provide good service to the people. The government expenditure should also be cut down according to the principle of "separating the functions of governments from enterprises and institutions".

3) Improving the examination system of political achievements and motivate the positivity of local governments in cultivated land protection. At present, the examination of political achievements focuses on the increase rate of GDP, developing scales of city and town, number of attracting investment and industrial projects. Under this situation, every government has to make its own political achievements so that many face projects are produced, which are mainly derived from the expansion of cultivated land occupancy of low cost. The resource consumption and ecological regression deciding the economic sustainability are totally neglected. The examination mechanism of political achievements which only focuses on the quantity of economic development should be totally changed. People-oriented economic sustainability should also be taken into consideration. The short-sighted behaviours of face projects and political achievement projects which only seek quick success and instant benefits should be eliminated altogether. The occupancy of cultivated land should be counted into the cost of national economy.

4) Exploring the compensation mechanism of cultivated land protection and realize the fairness of it in the whole society. With a large land area, China has an unbalanced space distribution. Besides, the scissor difference between industrial and agricultural products leads to the fact that areas with rich land resources becomes underdeveloped regions. However, cultivated land protection means that these areas have to give up many opportunities for industrial development in order to avoid the occupancy of cultivated land for industrialization. Therefore, they are trapped in the dilemma of "protect farmland is to maintain poverty", which runs counter to the fairness of cultivated land protection. So we have to positively explore the compensation mechanism of cultivated land protection by some macro-economic means of the country [21], such as transfer of financial payment and formulate scientific compensation measures, such as compensating the subjects, compensating the capital collection, compensating the amount accounting, compensating methods as well as compensating the supervising system. Furthermore, we should help the development of areas which are the main grain suppliers or whose land is occupied for construction use and give economic compensation to the underdeveloped protection areas of cultivated land so as to create a real fair environment of cultivated land protection in the whole society.

\section{ACKNOWLEDGMENT}

*This research is funded by the National Nature and Science Fund (No. 71163022).

\section{REFERENCES}

[1] Wang Shiyuan. The speech on " the protection of basic farmland in commemoration of 20 anniversary of the nineteenth national land day expert forum" [J]. land resource communication, 2009, (12): 47-49

[2] Yun Wenju, Zhang Rena, Cheng Feng. Basic farmland 20 years [J]. China land, 2009, (11): 51-53

[3] Zhang Hongyu, Huang Qizheng, Yan Rong. Review on the "Rice bag" the governor[J]. Chinese rural economy,1996(5):23-27

[4] Guo Wei, Wang Laiwu. Grain governor accountability: contradictions and problems of [J]. agricultural economy problem, 1998 (12): 2-6

[5] Li Xiubin. Change of arable land area in China during the past 20 years and its pol icy impl ications[J].Journal of natural resources, 1999, 14 (4):329-333

[6] Lester Brown. Who Will Feed China: Wake-Up Call for a Small Planet[R]. New York:W. W. Norton \& Company,1995

[7] Lin Pei, Cheng Ye. "Total dynamic balance of cultivated land" policy connotation and the realization way $[\mathrm{J}]$. China land science, 2001, 15 (3):12-14

[8] Huang Xianjin, Pu LiJie, Shang Guihua. The problems and reform proposals of total dynamic balance of cultivated land[J]. China land science, 2001, 15 (4):28-31

[9] Li Yanfang, Zhang Xia. Focus on cultivated land quality -Reflection on the policy of total dynamic balance of cultivated land[J]. Economic Forum 2004, (14):103-104

[10] Han xiong. "occupy one compensate one" policy should be adjusted [J]. China land, 2010, (1): 60

[11] Zheng Haixia, Feng Zhiming. Quantity and quality analysis of total dynamic balance of cultivated land in China [J]. Resources science, 2003, 25 (5): 33-39

[12] Zhang Yubao. Review on total dynamic balance of cultivated land [J]. China land, 2004 (12):20-22

[13] Zhang Xiaosong. Three warning signal on the decrease of cultivated land in China $[\mathrm{N}]$. Reference news - Beijing reference, 2006-4-18

[14] Jiang na. The quality of cultivated land: a problems can not be ignored [N]. farmer daily 2009-10-26 
[15] Gong Zitong, Chen Hongzhao, Zhang Ganlin et al. The protection of cultivated land: problems, causes and approaches [J]. ecology and environment, 2007, 16 (5): 1570-1573

[16] Chen Meiqiu, Zhou Bingjuan, Deng Aizhen. Thinking on Initiative of Farmer's on Cultivated Land Protection [J]. China population, resources and environment,2007, (1): 114-118

[17] Daniel H., Cynthia N, Joseph C.. Farmland Protection: TheRole of Pu blic Preferences for Rural Amenities[R]. AgriculturalEconomic Repor t No. 815 Washington, 2002

[18] Chen Meiqiu, Hong Lin, Xu Bingjie et al. On the social responsibility and countermeasures of cultivated land protection[J]. academic Journal of Zhongzhou , 2008 (5): 119-123

[19] Lu Xinhai, Huang Shanlin [J]. The problem and countermeasures of cultivated land protection in China[J]. Journal of Huazhong University, 2010,24 (3): 79-84

[20] Chen Meiqiu, Zhou Bingjuan, Xu Anqing. Promoting rural land function from security to capital transformation [J]. Journal of Jiangxi Agricultural University,2005, (4):16-18

[21] Zang Junmei, a Wenfang, Li Jinggang. Dynamic equilibrium of the total cultivated land under the regional compensation mechanism of cultivated land protection of $[\mathrm{J}]$. Agricultural modernization research, 2008, 29 (3): 318-322 